\title{
Hot consolidated all-PP composites from textile fabrics composed of isotactic PP filaments with different degrees of orientation
}

\author{
A. Izer, T. Bárány* \\ Department of Polymer Engineering, Faculty of Mechanical Engineering, Budapest University of Technology and \\ Economics, H-1111 Budapest, Múegyetem rkp. 3., Hungary
}

Received 27 July 2007; accepted in revised form 29 September 2007

\begin{abstract}
Self-reinforced polypropylene composites (SRPPC) were hot pressed from textile layers (carded mat, knitted fabrics) at three different temperatures $\left(160,165\right.$ and $\left.170^{\circ} \mathrm{C}\right)$ by setting a constant pressure $(6 \mathrm{MPa})$ and constant holding time ( $2 \mathrm{~min}$ ). Both textiles consist of two kinds of isotactic polypropylene (iPP) fibers differing in their orientation. In these compositions the highly oriented iPP works as reinforcement and the less oriented one fulfills the role of the matrix after hot consolidation. Two textile assemblies, viz. carded (also needle punched) mats and knitted fabrics were hot pressed; and the properties of the resultant SRPPC plates were investigated under tensile and falling weight impact conditions. The microstructure of the SRPPC was analyzed by light microscopy using polished sections and by SEM using cut surfaces.
\end{abstract}

Keywords: polymer composites, self-reinforcement, consolidation, textile fabric, polypropylene

\section{Introduction}

Nowadays the most frequently used reinforcement in the automotive industry is glass fiber (GF) applied mainly in polypropylene (PP) and polyamide (PA) matrices. In spite of the excellent mechanical properties of glass fiber reinforced polymer composites, the main disadvantage is their limited recyclability. The importance of recycling forced the researchers to develop more environment-friendly solutions. Self-reinforced polymer composites (SRPC) tend to be one of the best choices, so the research and the development of these composites is an extensively studied topic nowadays. SRPCs are composed of reinforcing fabrics made of highly oriented technical fibers and a matrix material. Recall that they are of the same polymer. The key issue of their manufacturing is to find a suitable processing window that ensures that the reinforcing fibers do not melt (or only partially) and the matrix wets them out accordingly [1-4]. The focus of many research works is to widen this window. In case of SRP composites, three concepts are used. The first technique is hot compaction, where the outer layer of the fibers melts and recrystallizes as a matrix in a suitable temperature and pressure range $[1,5,6]$. The second one is co-extrusion, where a thin layer with lower melting temperature is co-extruded with a highly oriented, thicker core, and these bands are textile structured and hot consolidated [2, 7-9]. Finally, there is the filmstacking method, where the matrix and reinforcement layers are laminated onto each other and are hot pressed $[3,4,10,11]$. In case of the film-stacking method, the material selection and combination is more flexible and the composite production can also made continuously by using a double belt press. In case of the latter two methods the melting temperature difference $\left(20-30^{\circ} \mathrm{C}\right.$; in case of $\left.\mathrm{PP}\right)$ can be

*Corresponding author, e-mail: barany@pt.bme.hu

(C) BME-PT and GTE 
reached if random PP copolymer/isotactic PP (iPP) [2, 3, 7-12]; beta polymorph of iPP/iPP fiber [4] combinations are used. Furthermore, the processing window is narrower $\left(7-8^{\circ} \mathrm{C}\right)$ if various iPP fibers having different stretching ratios (orientation degrees) are used. As far as we know there are no studies on the manufacturing of SRPCs exploiting the last mentioned possibility. Therefore, our aim is to investigate the hot consolidation of carded (and needle punched) mats and knitted fabrics. Both textiles consist of two kinds of oriented iPP fibers. In these compositions the highly oriented material should work as reinforcement and the less oriented one should fulfill the role of the matrix after hot pressing. The textile layers were hot consolidated (hot pressed) at three different temperatures (160, 165 and $\left.170^{\circ} \mathrm{C}\right)$ at constant pressure $(6 \mathrm{MPa})$ and for constant holding time $(2 \mathrm{~min})$. Tensile and instrumented falling weight impact test were performed on the composite sheets.

\section{Experimental}

\subsection{Materials and their processing}

Slightly oriented iPP fiber produced by Sopilén Ltd. (Sopron, Hungary) was used as the matrix and highly oriented iPP fibers manufactured by
Stradom S.A. (Czestochowa, Poland) as the reinforcement. Tensile test $\left(100 \mathrm{~mm} / \mathrm{min}, 23^{\circ} \mathrm{C}\right)$ and differential scanning calorimetry tests $\left(10^{\circ} \mathrm{C} / \mathrm{min}\right)$ were performed on the single fibers. The related results are listed in Table 1. In this study we mark the reinforcing fibers as highly oriented and the matrix fiber as slightly oriented. Although, we have no information about the degree of orientation but from the testing results (single fiber) this characteristic can be concluded. Note that the observed difference in the melting temperatures ensures the targeted manufacturing of self reinforced polypropylene composites (SRPPC).

Two different textile fabrics were used for SRPPC sheets. (i) Plain weft knitted fabric (becoming the matrix) with in-laid iPP fiber reinforcement was prepared from the fibers (cf. Figure 1). Note that the reinforcing contents were set to be 24 and $38 \mathrm{wt} \%$ determined by the nominal weight of the reinforcing fibers used. (ii) Chopped $(\approx 80 \mathrm{~mm})$ matrix giving and as reinforcement working fibers were carded and needle punched together as described in details in Ref. [12] (hereafter referred to as: carded - it is shown on Figure 1). The identical textile layers (in case of knitted 8, in case of carded 4 plies) were placed on each other by keeping the reinforcement alignment constant; therefore
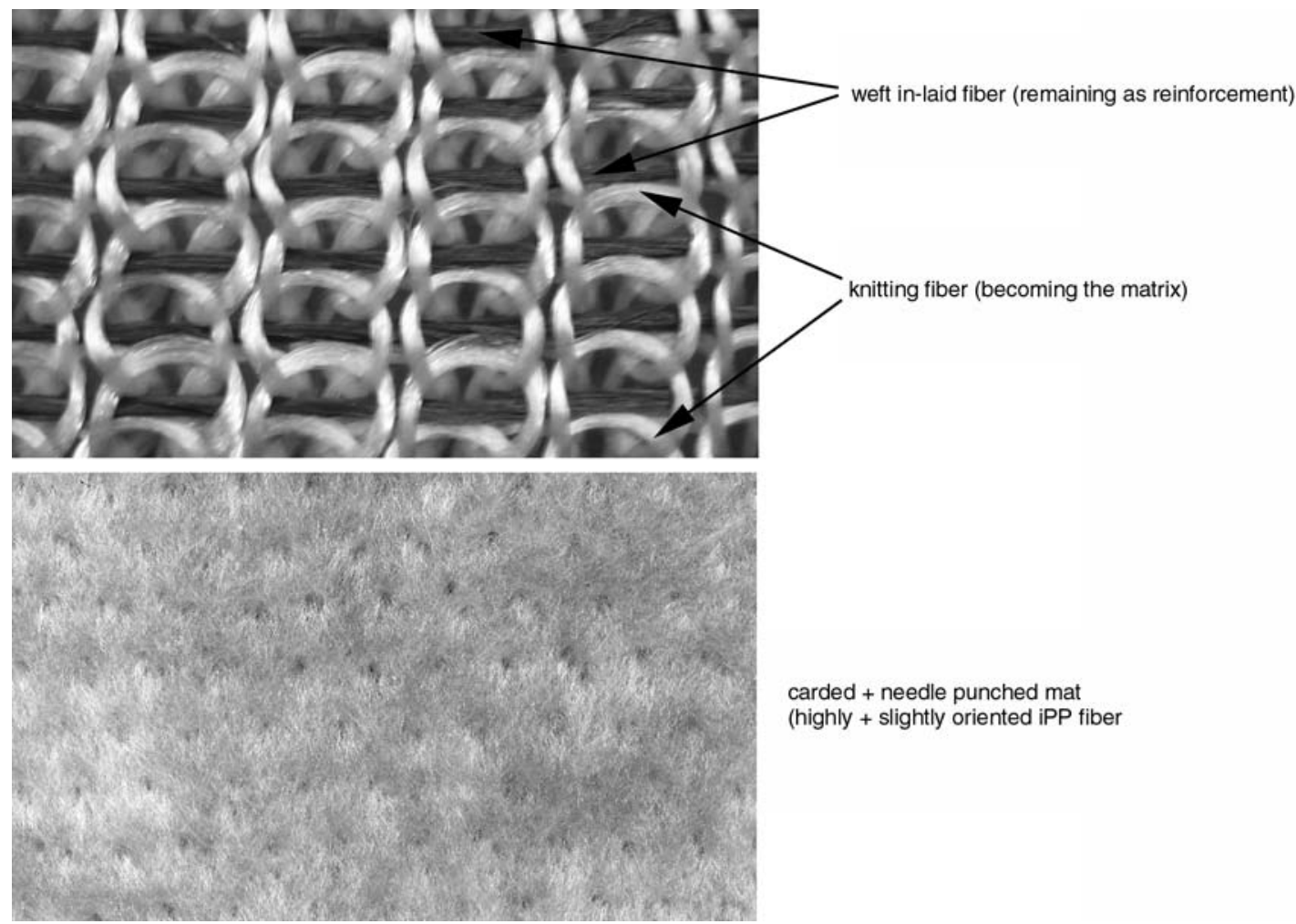

carded + needle punched mat

(highly + slightly oriented iPP fiber

Figure 1. The scheme of the plain weft knitted fabric with in-laid iPP fiber reinforcement (hereafter referred to as: knitted fabric) and carded and needle punched mat 
Table 1. The properties of the matrix and reinforcing fibers

\begin{tabular}{|c|c|c|c|c|c|}
\hline Fiber & $\begin{array}{c}\text { Tensile } \\
\text { strength } \\
{[\mathbf{M P a}]}\end{array}$ & $\begin{array}{c}\text { Tensile } \\
\text { modulus } \\
{[\mathbf{G P a}]}\end{array}$ & $\begin{array}{c}\text { Average } \\
\text { diameter } \\
{[\boldsymbol{\mu m}]}\end{array}$ & $\begin{array}{c}\text { Melting } \\
\text { temperature } \\
\left(\mathbf{1}^{\text {st }} \text { run) }\left[{ }^{\circ} \mathbf{C}\right]\right.\end{array}$ & $\begin{array}{c}\text { Melting } \\
\text { temperature } \\
\left(\mathbf{2}^{\text {nd }} \mathbf{\text { run} )}\left[{ }^{\circ} \mathbf{C}\right]\right.\end{array}$ \\
\hline $\begin{array}{c}\text { Reinforcing fiber (2200 dtex, white) } \\
\text { for knitted fabric and carded mat }\end{array}$ & $465 \pm 32$ & $3.7 \pm 0.3$ & $40.2 \pm 1.8$ & 178.9 & 165.7 \\
\hline $\begin{array}{c}\text { Reinforcing fiber (1200 dtex, black) } \\
\text { for knitted fabric }\end{array}$ & $440 \pm 42$ & $3.9 \pm 0.4$ & $40.3 \pm 3.6$ & 178.4 & 164.2 \\
\hline $\begin{array}{c}\text { Matrix fiber (600 dtex, white) } \\
\text { for carded mat }\end{array}$ & $89 \pm 11$ & $0.9 \pm 0.1$ & $58.4 \pm 3.7$ & 170.5 & 165.5 \\
\hline $\begin{array}{c}\text { Matrix fiber (2100 dtex, white) } \\
\text { for knitted fabric }\end{array}$ & $148 \pm 25$ & $1.9 \pm 0.3$ & $45.5 \pm 3.0$ & 171.0 & 163.4 \\
\hline
\end{tabular}

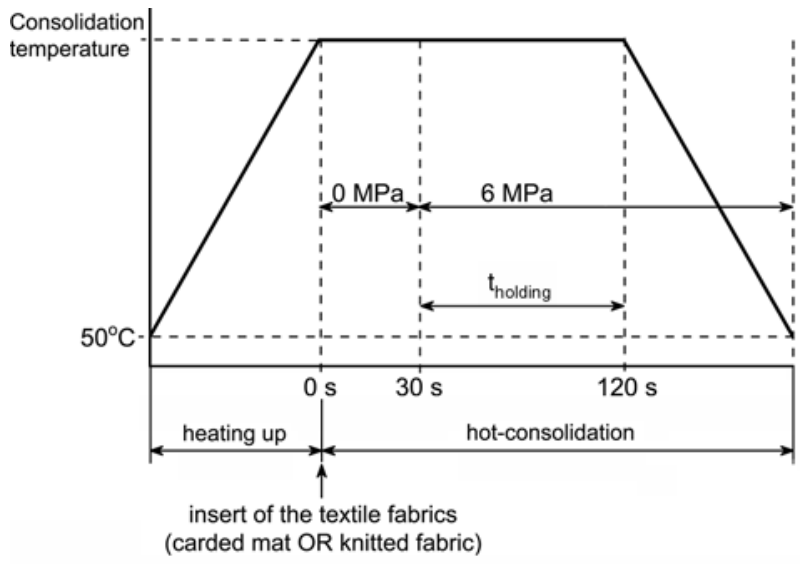

Figure 2. The parameters of the composite processing (consolidation)

the resulting composite plates are of anisotropic nature. These packages were consolidated by hot pressing at three different temperatures $(160,165$ and $\left.170^{\circ} \mathrm{C}\right)$ at constant pressure $(6 \mathrm{MPa})$ and for constant holding time ( $2 \mathrm{~min}$ ). The detailed settings of the hot pressing process are shown in Figure 2. The thickness of the manufactured composite sheets is approximately $3 \mathrm{~mm}$.

\subsection{Specimens and their testing}

The consolidation quality was studied on polished cross sections of the SRPPC sheets via reflection light microscopy (LM; Olympus BX51M).

The cut surface of the specimens was inspected in a scanning electron microscope (SEM; JEOL 6380 LA, Japan) after sputtering with $\mathrm{Au} / \mathrm{Pd}$ alloy.

Static tensile and dynamic falling weight impact tests were performed on the manufactured composite sheets. The tensile tests were done on a universal ZWICK Z020 testing machine according to standard EN ISO 527. Tensile strength was determined from the tests results. Instrumented falling weight impact (IFWI) tests were performed on a
Fractovis 3789 (Ceast, Italy) machine with the following settings: maximal energy: $229.05 \mathrm{~J}$; diameter of the dart: $20 \mathrm{~mm}$; diameter of the support rig: $40 \mathrm{~mm}$; weight of the dart: $23.62 \mathrm{~kg}$ and drop height: $1 \mathrm{~m}$. IFWI specimens were quadratic, with a size of $70 \times 70 \mathrm{~mm}^{2}$. Each test was performed at room temperature $\left(23^{\circ} \mathrm{C}\right)$, in weft (for knitted fabric) and fiber direction (for carded mat).

\section{Results and discussion}

\subsection{Microstructure characterization}

Figures 3 and 4 show the LM pictures of the polished cross section of the hot consolidated knitted fabric $\left(24.3 \mathrm{wt} \% ; 160\right.$ and $\left.170^{\circ} \mathrm{C}\right)$ and carded $(30$, 50 and $70 \mathrm{wt} \% ; 160$ and $170^{\circ} \mathrm{C}$ ). Figures 3 and 4 reveal that the matrix fibers have melted partially at $160^{\circ} \mathrm{C}$, while continuous matrix can be detected at the processing temperature of $170^{\circ} \mathrm{C}$. For carded mat-based SRPPCs the reinforcing fibers distribute well in case of $30 \mathrm{wt} \%$ at each temperature but as the reinforcing fiber content increases, significant segregation of fibers can be seen and the fibers are distributed more homogenously only at the highest temperature $\left(170^{\circ} \mathrm{C}\right)$.

Figure 5 shows the SEM (magnification of 100x) pictures of the cut surface of the SRPPCs produced from the knitted fabric (38.2 wt $\%$ ) and Figure 6 displays SEM pictures (magnification of $100 \times$ ) of the cut surface of the SRPPCs produced from the carded mat $(50 \mathrm{wt} \%)$ manufactured at 160 and $170^{\circ} \mathrm{C}$, respectively. In both cases it can be seen well that with increasing processing temperature, the matrix fibers melted to a greater extent, hence consolidation improved. In other words, with increasing processing temperature, the matrix wets the reinforcing fibers more and better adhesion can be supposed. 


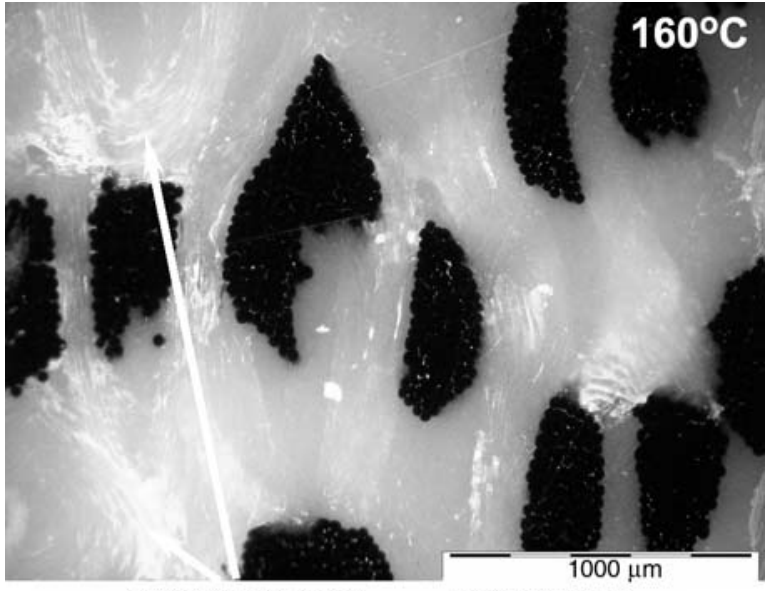

partially molten matrix

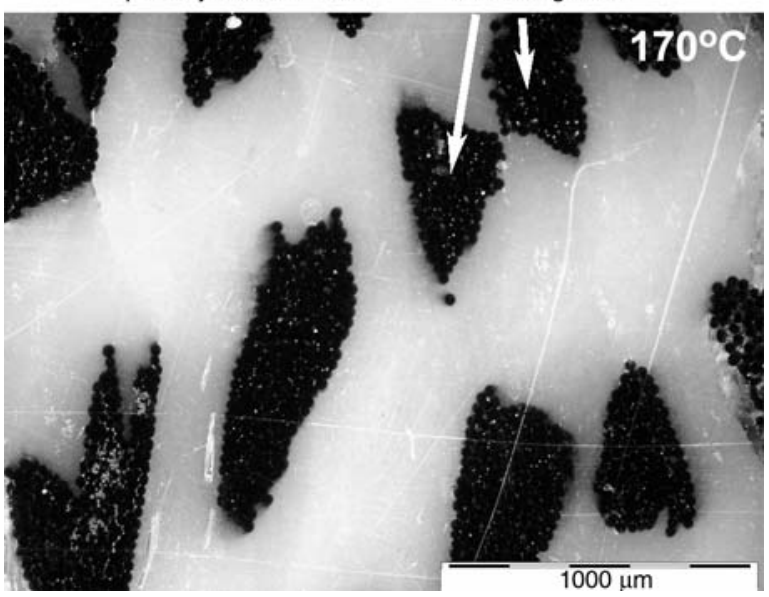

Figure 3. Light microscopic pictures of the polished cross section of the hot consolidated knitted fabric (nominal reinforcing content: $24.3 \mathrm{wt} \%$ ) manufactured at 160 and $170^{\circ} \mathrm{C}$

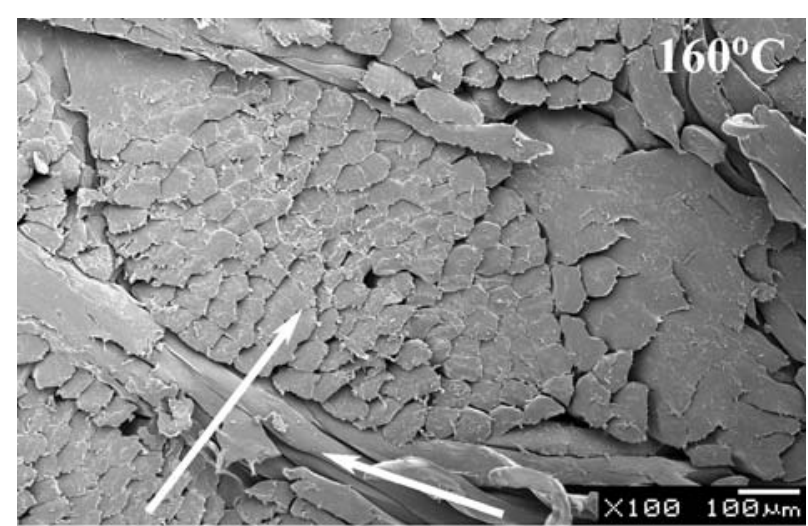

Reinforcing fibers

Matrix

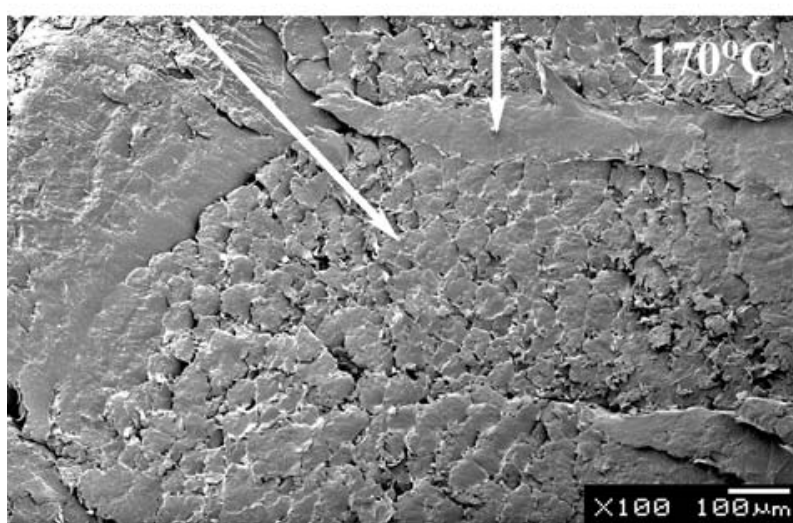

Figure 5. Scanning electron microscopic pictures of the cut cross section of the hot consolidated (at 160 and $170^{\circ} \mathrm{C}$ ) knitted fabric (nominal reinforcing content: $38.2 \mathrm{wt} \%$ )

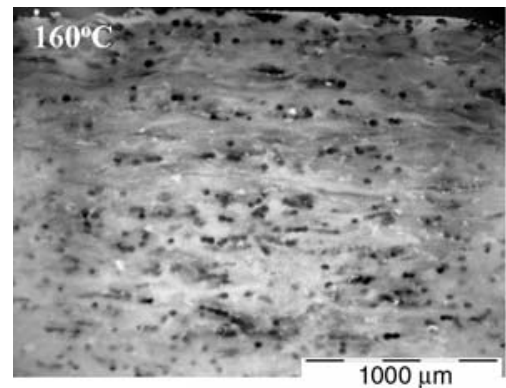

$30 \mathrm{wt} \%$

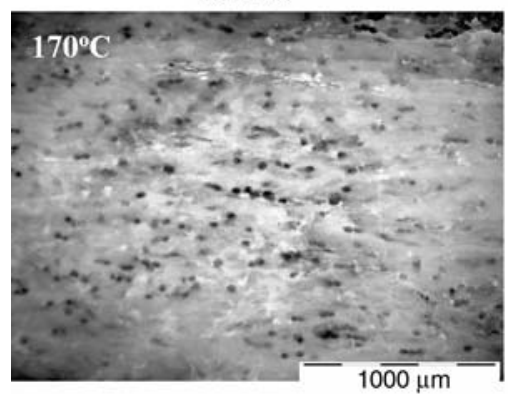

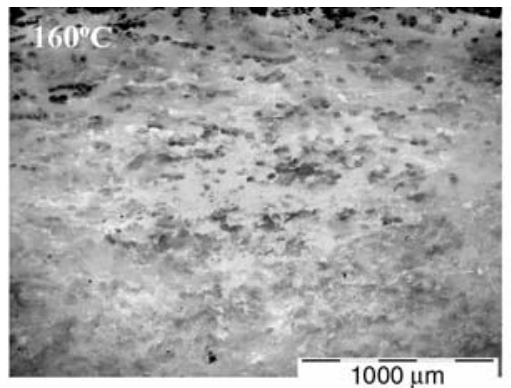

$50 w+\%$

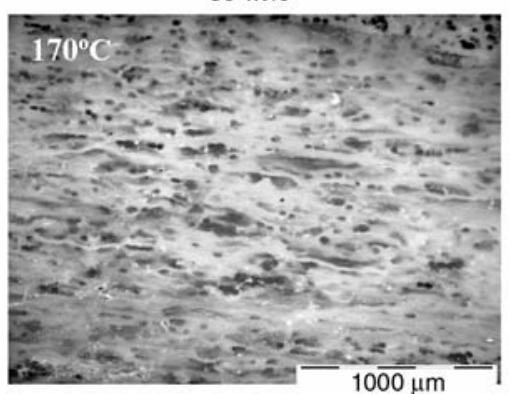

$\mathrm{R} 1$

$\mathrm{R} 2$

Figure 4. Light microscopic pictures of the polished cross section of the hot consolidated carded mat (nominal reinforcing content: 30,50 and $70 \mathrm{wt} \%$ ) manufactured at 160 and $170^{\circ} \mathrm{C}$ 


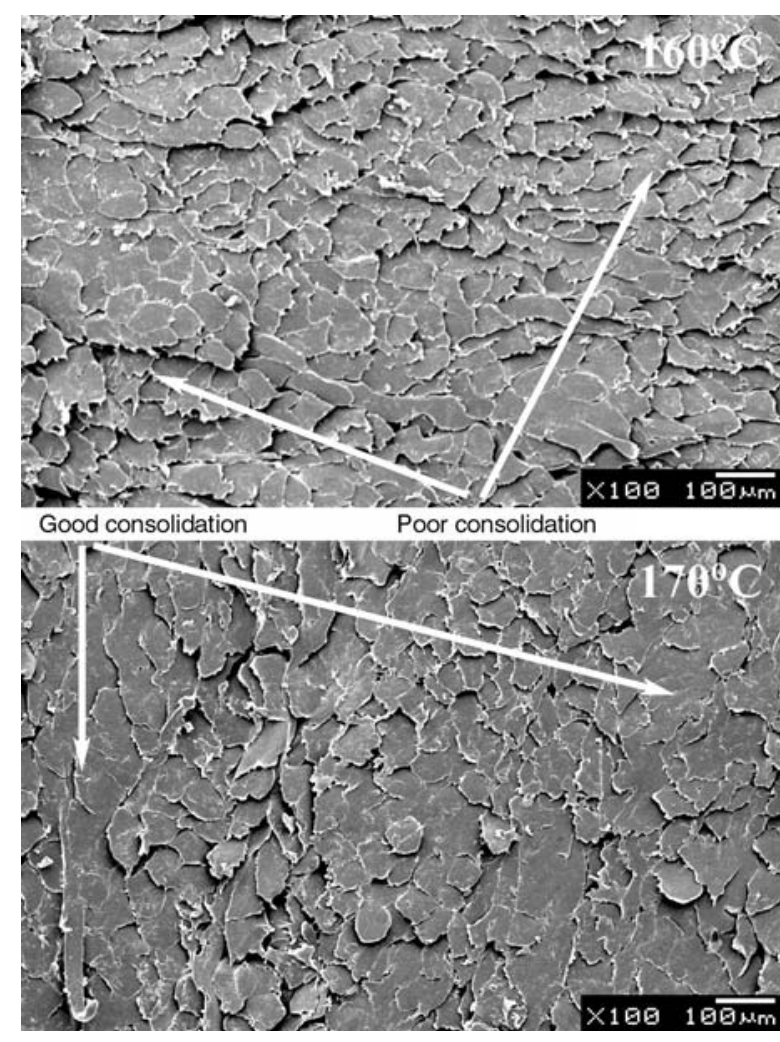

Figure 6. Scanning electron microscopic pictures of the cut cross section of the hot consolidated (at 160 and $170^{\circ} \mathrm{C}$ ) carded mat (nominal reinforcing content: $50 \mathrm{wt} \%$ )

\subsection{Static and dynamic tests}

The results of the mechanical tests are listed in Table 2. Figures 7 and 8 show the tensile strength as a function of the processing temperature for knitted fabrics and carded mat-based SRPPCs, respectively. For both structures, as expected, the tensile

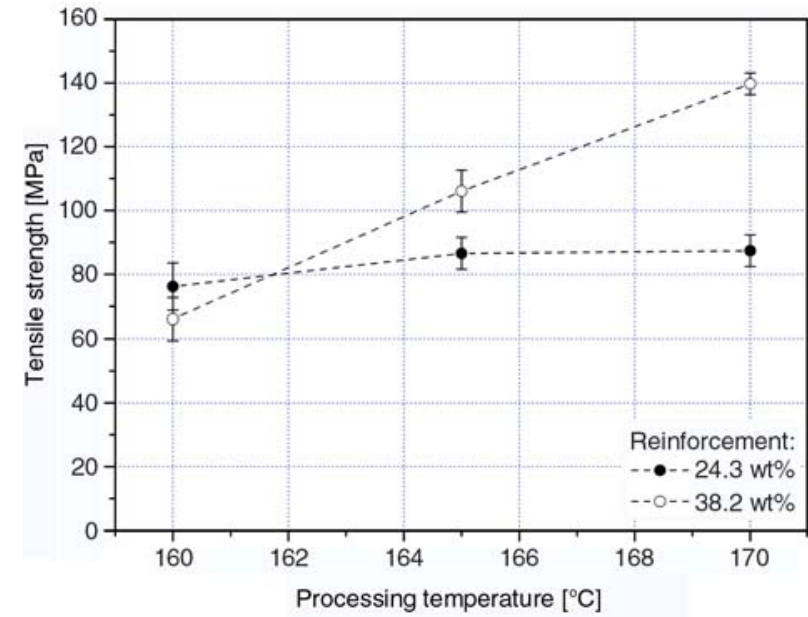

Figure 7. Tensile strength vs. processing temperature determined on the hot consolidated knitted fabrics

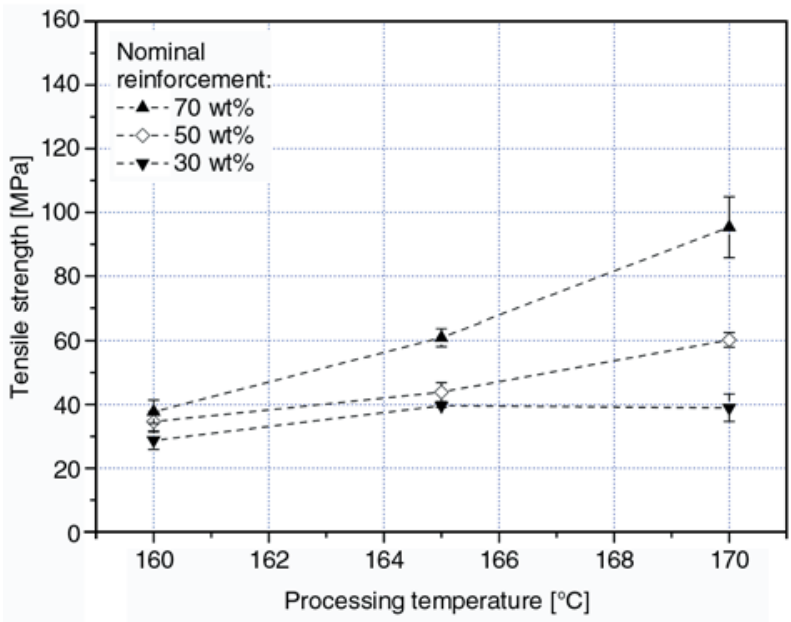

Figure 8. Tensile strength vs. processing temperature determined on the hot consolidated carded mat

Table 2. Mechanical properties of the manufactured composites

\begin{tabular}{|c|c|c|c|c|c|}
\hline Composite build-up & $\begin{array}{c}\text { Nominal } \\
\text { fiber content } \\
{[w t \%]}\end{array}$ & $\begin{array}{c}\text { Consolidation } \\
\text { temperature } \\
{\left[{ }^{\circ} \mathrm{C}\right]}\end{array}$ & $\begin{array}{c}\text { Tensile } \\
\text { strength } \\
\text { [MPa] }\end{array}$ & $\begin{array}{c}\text { Tensile } \\
\text { modulus } \\
{[\mathrm{MPa}]}\end{array}$ & $\begin{array}{c}\text { Perforation } \\
\text { energy } \\
{[\mathrm{J} / \mathrm{mm}]}\end{array}$ \\
\hline \multirow{3}{*}{$\begin{array}{c}\text { Knitted } \\
\text { (black reinforcing fiber) }\end{array}$} & \multirow{3}{*}{24.3} & 160 & $76.2 \pm 7.4$ & $2391 \pm 244$ & $19.6 \pm 1.4$ \\
\hline & & 165 & $86.6 \pm 5.0$ & $2269 \pm 85$ & $19.9 \pm 1.5$ \\
\hline & & 170 & $87.4 \pm 5.0$ & $2513 \pm 46$ & $19.9 \pm 4.9$ \\
\hline \multirow{3}{*}{$\begin{array}{c}\text { Knitted } \\
\text { (white reinforcing fiber) }\end{array}$} & \multirow{3}{*}{38.2} & 160 & $66.1 \pm 6.7$ & $2311 \pm 156$ & $22.6 \pm 1.6$ \\
\hline & & 165 & $106.1 \pm 6.6$ & $2353 \pm 57$ & $22.1 \pm 3.4$ \\
\hline & & 170 & $139.7 \pm 3.4$ & $2486 \pm 55$ & $9.9 \pm 1.7$ \\
\hline \multirow{3}{*}{$\begin{array}{c}\text { Carded } \\
\text { (white reinforcing fiber) }\end{array}$} & \multirow{3}{*}{30} & 160 & $28.8 \pm 2.9$ & $2131 \pm 74$ & $18.4 \pm 2.5$ \\
\hline & & 165 & $39.6 \pm 0.5$ & $2159 \pm 40$ & $16.1 \pm 0.8$ \\
\hline & & 170 & $39.0 \pm 4.3$ & $2161 \pm 10$ & $15.1 \pm 2.4$ \\
\hline \multirow{3}{*}{$\begin{array}{c}\text { Carded } \\
\text { (white reinforcing fiber) }\end{array}$} & \multirow{3}{*}{50} & 160 & $34.6 \pm 3.2$ & $2247 \pm 83$ & $20.0 \pm 4.2$ \\
\hline & & 165 & $43.9 \pm 3.0$ & $2218 \pm 59$ & $18.4 \pm 3.5$ \\
\hline & & 170 & $60.3 \pm 2.3$ & $2480 \pm 68$ & $11.6 \pm 2.2$ \\
\hline \multirow{3}{*}{$\begin{array}{c}\text { Carded } \\
\text { (white reinforcing fiber) }\end{array}$} & \multirow{3}{*}{70} & 160 & $37.7 \pm 3.7$ & $2425 \pm 90$ & $25.1 \pm 1.2$ \\
\hline & & 165 & $60.9 \pm 2.8$ & $2387 \pm 99$ & $20.4 \pm 0.5$ \\
\hline & & 170 & $95.4 \pm 9.6$ & $2837 \pm 62$ & $16.3 \pm 2.7$ \\
\hline
\end{tabular}


strength increases with increasing processing temperature and with increasing reinforcing fiber content. According to our earlier studies $[4,11,12]$ the tensile parameters (strength, modulus) decreased at temperatures higher than $170^{\circ} \mathrm{C}$ owing to the relaxation and partial melting of the reinforcing fibers. So, in our present study we have focused on the processing temperature range of $160-170^{\circ} \mathrm{C}$. For better consolidation of the increasing reinforcing fiber content, matrix material having lower viscosity is demanded which is the result of the higher temperature. Therefore the tensile parameters depends more on the processing temperature with increasing reinforcement ratio.

Figures 9 and 10 show the perforation energy $v s$. processing temperature for knitted fabrics and carded mat-based SRPPCs, respectively. In case of carded mat-based SRPPCs - as expected - the per-

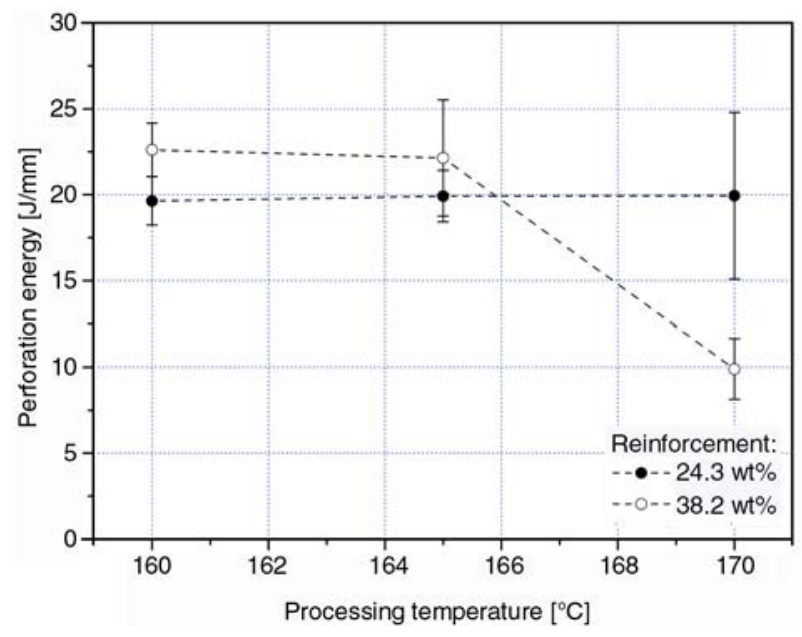

Figure 9. Perforation energy vs. processing temperature determined on the hot consolidated knitted fabrics

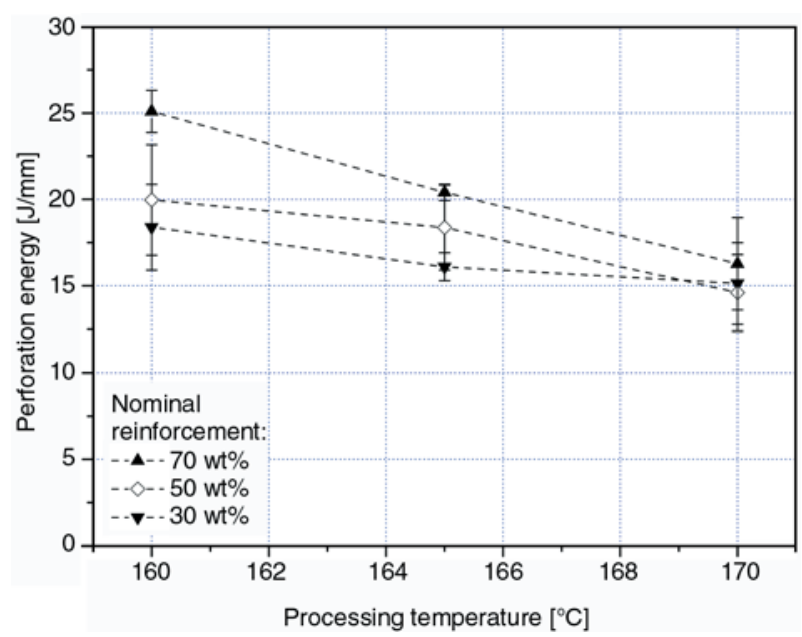

Figure 10. Perforation energy vs. processing temperature determined on the hot consolidated carded mat foration energy decreases - especially at higher reinforcement content - with increasing processing temperature content, and this refers to the improvement of consolidation. Note that the poorly consolidated system absorbs higher energy up to the failure than the better consolidated one. This can be advantageous for special applications. The results of IFWI tests performed on knitted fabric-based SRPPC sheets are twofold. First, the values are as high as for carded-based SRPPCs with significant deviation. Second, the typical failure of these specimens (knitted fabric-based) is the total pull out of the in-laid reinforcing fibers and at the highest processing temperatures the specimen tears at the whole length along the in-laid reinforcing fibers (in weft direction) (Figure 11), even at increased specimen dimensions $(90 \times 90 \mathrm{~mm})$. In case of cardedbased SRPPC specimens (IFWI) the same behavior was experienced as in our earlier studies $[4,11]$ : when the composite is consolidated at lower processing temperature, massive delamination took place while the SRPPC sheets produced at higher processing temperature are less prone to delamination but exhibited markedly lower energy dissipation.

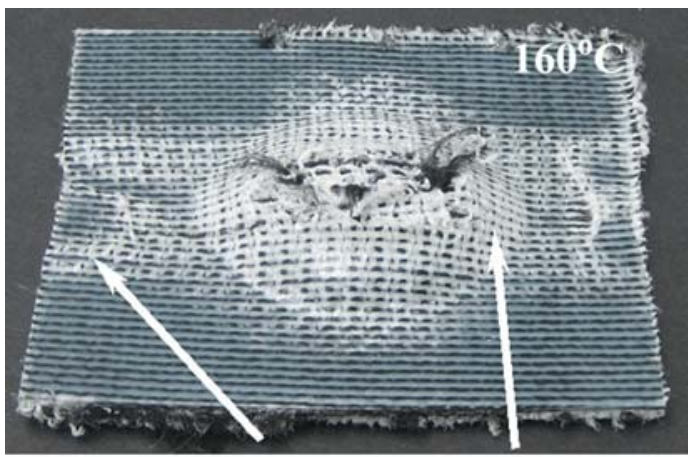

pull out of the reinforcing fibers and delamination

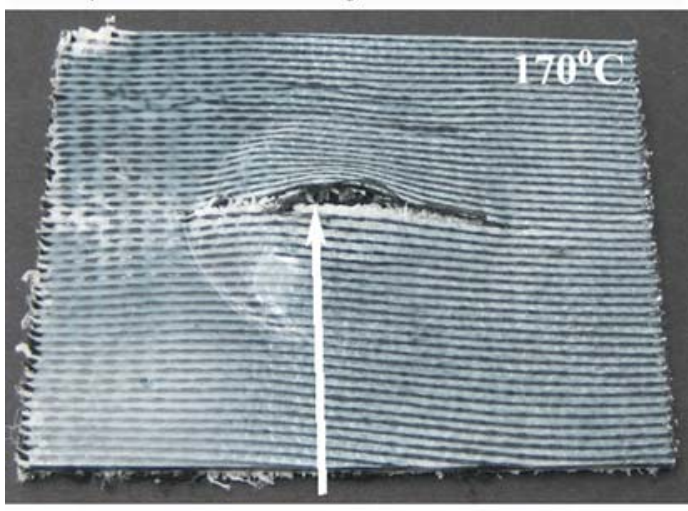

ripping along the reinforcing fiber

Figure 11. Typical failure behavior of knitted IFWI specimens of knitted fabric-based SRPPCs (produced at 160 and $170^{\circ} \mathrm{C}$ ) 
To compare the knitted fabric and carded matbased SRPPCs, it can be stated that the tensile strength is much higher for knitted fabric-based SRPPCs (38 wt\%) than the carded mat-based one (70 wt \%), but there is no considerable difference in perforation energy values. The cause of the difference in tensile strength can be the fact that the knitted fabrics are composed of continuous fibers while carded mats contain chopped fibers.

\section{Conclusions}

Self-reinforced polypropylene composites (SRPPC) were prepared by hot consolidation of knitted fabrics and carded mats with different reinforcement content. Both kinds of textile structures were consolidated by hot pressing at different temperatures $\left(160,165\right.$ and $\left.170^{\circ} \mathrm{C}\right)$ at constant pressure $(6 \mathrm{MPa})$ and for constant holding time ( $2 \mathrm{~min})$. The consolidation quality of the resulting composite sheets was studied on polished and cut cross section with light and scanning electron microscopes, respectively. Static tensile and dynamic falling weight impact tests were performed on the composite plates. Based on the results the following conclusions can be drawn:

1. With the set processing parameters, the selected and applied matrix fiber / reinforcing fiber combinations are suitable for forming self-reinforced polymer composites with excellent mechanical properties (in reinforcing fiber direction).

2. According to the LM and SEM pictures it can be stated that the matrix fibers have melted at the highest temperature $\left(170^{\circ} \mathrm{C}\right)$ and formed the matrix in which the reinforcing fibers or roving (for knitted fabrics) are embedded therefore better adhesion can be supposed.

3. In case of higher reinforcing contents, the processing (hot consolidation) temperature influences the tensile strength and perforation energy the most significantly for both textile structures.

4. The knitted fabric-based SRPPCs containing continuous reinforcing iPP fiber posses better mechanical properties than the carded matbased version containing discontinuous reinforcing iPP fibers even if the reinforcement content of the latter is much higher.

\section{Acknowledgements}

This work was supported by the János Bolyai Research Scholarship of the Hungarian Academy of Sciences and the Hungarian Scientific Research Fund (OTKA F60505 and NI62729).

\section{References}

[1] Ward I. M., Hine P. J.: The science and technology of hot compaction. Polymer, 45, 1423-1437 (2004).

[2] Peijs T.: Composites for recyclability. Materials Today, 6, 30-35 (2003).

[3] Houshyar S., Shanks R. A., Hodzic A.: Influence of different woven geometry in poly(propylene) woven composites. Macromolecular Materials and Engineering, 290, 45-52 (2005).

[4] Bárány T., Karger-Kocsis J., Czigány T.: Development and characterization of self-reinforced poly (propylene) composites: carded mat reinforcement. Polymers for Advanced Technologies, 9-10, 818-824 (2006).

[5] Hine P. J., Ward I. M., Jordan N. D., Olley R., Bassett D. C.: The hot compaction behaviour of woven oriented polypropylene fibres and tapes. I. Mechanical properties. Polymer, 44, 1117-1131 (2003).

[6] Ward I. M.: Developments in oriented polymers, 1970-2004. Plastics, Rubber and Composites, 33, 189-194 (2004).

[7] Alcock B., Cabrera N. O., Barkoula N-M., Loos J., Peijs T.: The mechanical properties of unidirectional all-polypropylene composites. Composites, Part A: Applied Science and Manufacturing, 37, 716-726 (2006).

[8] Alcock B., Cabrera N. O., Barkoula N-M., Loos J., Peijs T.: Interfacial properties of highly oriented coextruded polypropylene tapes for the creation of recyclable all-polypropylene composites. Journal of Applied Polymer Science, 104, 118-129 (2007).

[9] Abraham T., Banik K., Karger-Kocsis J.: All-PP composites $\left(\mathrm{PURE}^{\circledR}\right)$ with unidirectional and cross-ply lay-ups: dynamic mechanical thermal analysis. Express Polymer Letters, 1, 519-526 (2007).

[10] Houshyar S., Shanks R. A.: Tensile properties and creep response of polypropylene fibre composites with variation of fibre diameter. Polymer International, 53, 1752-1759 (2004).

[11] Bárány T., Izer A., Czigány T.: High performance self-reinforced polypropylene composites. Materials Science Forum, 537-538, 121-128 (2007).

[12] Bárány T., Izer A., Czigány T.: On consolidation of self-reinforced polypropylene composites. Plastics, Rubber and Composites, 35, 375-379 (2006). 